УДК 614.843

ИССЛЕДОВАНИЕ ПОЖАРНОЙ ОПАСНОСТИ ДЕРЕВЯННЫХ

СТРОИТЕЛЬНЫХ КОНСТРУКЦИЙ И МАТЕРИАЛОВ

ПРИ ПРИМЕНЕНИИ ЭФФЕКТИВНЫХ

ОГНЕЗАЩИТНЫХ СРЕДСТВ

\title{
INVESTIGATION OF FIRE HAZARD OF WOODEN BUILDING STRUCTURES AND MATERIALS WHEN USING EFFECTIVE FIRE PROTECTION AGENTS
}

А.М. Газизов, А.А. Шарафутдинов, С.А. Имамутдинов, Г.А. Горячев, А.А. Шарафутдинова

Уфимский государственный нефтяной технический университет, г. Уфа, Российская Федерация

Asgat M. Gazizov, Azat A. Sharafutdinov, Salavat A. Imamutdinov, Grigori A. Goryachev, Angela A. Sharafutdinova

Ufa State Petroleum Technological University, Ufa, Russian Federation

e-mail: azat_sharaf@mail.ru

Аннотация. Целью исследования являются создание нового высокоэффективного состава для древесины на основе недорогих материалов. Его применение позволит повысить уровень пожарной безопасности строительных объектов.

В ходе исследования проведён анализ существующих средств огнезащиты, определены достоинства и недостатки существующих средств огнезащиты, разработан новый огнезащитный состав для древесины и материалов на ее основе. 
Предметом исследования является определение пожарной опасности строительных конструкций и материалов при применении эффективных огнезащитных средств.

К наиболее существенным результатам исследования можно отнести выявленные тенденции развития огнезащитных средств для строительных конструкций и материалов из древесины, разработку нового огнезащитного состава для строительных конструкций из древесины и материалов на ее основе и достижение необходимой огнезащитной эффективности разработанного состава.

Abstract. The aim of the research is to create a new highly effective composition for wood based on inexpensive materials. Its use will increase the level of fire safety of construction sites.

The study was the analysis of existing means of fire protection, identified the advantages and disadvantages of existing means of fire protection, developed a new flame retardant for wood and materials based on it.

The subject of the study is the study of fire hazard of building structures and materials when using effective fire protection agents. The most significant results of the study can be attributed to the development trends of flame retardant for construction structures and materials from wood, proposed new fire retardant composition for building structures of wood and materials on its basis and achieve the necessary fire resistance performance of the developed composition.

Ключевые слова: огнезащитный состав; огнестойкость; огнезащитная эффективность; строительные конструкции; пожар; диоксид кремния; жидкое стекло

Key words: fire-retardant composition; fire resistance; fire-retardant efficiency; building structures; fire; silicon dioxide; liquid glass 
В статье представлен новый высокоэффективный состав для древесины на основе недорогих материалов. Его применение позволит повысить уровень пожарной безопасности строительных объектов $[1,2]$.

В России за 2018 г. произошло более 133 тыс. пожаров, погибло более 7 тыс. человек, материальный ущерб от пожаров составил более 14 млн руб. [3]. Людские и материальные потери происходят за счет обрушения строительных конструкций, поэтому большое внимание уделяется огнезащите конструкций с целью предупреждения их преждевременного обрушения.

Средства огнезащиты классифицируются по [2]:

- виду материала объекта огнезащиты;

- способу огнезащитной обработки;

- условиям эксплуатации;

- виду огнезащитного покрытия.

В зависимости от вида материала средства огнезащиты подразделяются на средства, предназначенные для [4-9]:

- древесины и материалов на ее основе;

- металла и изделий из него (воздуховодов и т.п.);

- тканей, нетканых материалов и ковровых покрытий;

- оболочек электрокабелей;

- полимерных и других материалов.

По способу огнезащитной обработки средства огнезащиты подразделяются на:

- пропиточные составы и антипирены;

- покрытия;

- комбинированные.

В зависимости от условий эксплуатации средства огнезащиты подразделяются на предназначенные для:

- сухих отапливаемых помещений;

- условий повышенной влажности; 
- атмосферных условий;

- специальных условий.

Средства огнезащиты по виду огнезащитного покрытия подразделяются на:

- обмазки;

- краски, лаки и пропиточные составы;

- антипирены [3].

Целью исследования являются создание нового высокоэффективного состава для древесины на основе недорогих материалов [1].

Его применение позволит повысить уровень пожарной безопасности строительных объектов.

Для достижения поставленной цели исследования необходимо было решить следующие задачи:

- провести анализ существующих средств огнезащиты;

- выявить достоинства и недостатки существующих средств огнезащиты;

- на основе проведенных анализов предложить новый огнезащитный состав (ОС) для древесины и материалов на ее основе.

- Объектом исследования выступают огнезащитные составы для древесины.

Наиболее существенные результаты исследования:

- проведен патентный обзор огнезащитных составов [10-18];

- выявлены тенденции развития огнезащитных средств для строительных конструкций и материалов из древесины;

- изучена методика исследования огнезащитных составов и веществ для древесины и материалов на ее основе;

- предложен новый огнезащитный состав для строительных конструкций из древесины и материалов на ее основе;

- определена огнезащитная эффективность разработанного состава.

Элементы научной новизны исследования состоят в следующем: 
- определены способы повышения огнезащитной эффективности;

- предложен новый огнезащитный состав на основе наноразмерного структурного наполнителя.

Практическая значимость исследования обусловлена возможностью применения полученного огнезащитного состава для строительных конструкций из древесины и изделий на ее основе, использующихся в строительстве.

\section{1. Экспериментально-теоретические исследования огнезащитных} свойств разработанного состава

Исследования на моделях (на малых образцах элементов конструкций) производилось на огнезащитном составе, которому было присвоено наименование «Спутник-2020».

Основная цель данных исследований - определить группу огнезащитной эффективности состава при тепловом воздействии в зависимости от количества нанесенных слоев.

Соотношение компонентов использовалось как в прототипе, соотношение составило 5-6 \% диоксида кремния, жидкое стекло остальное.

При проведении испытаний использовались деревянные брусочки размерами $150 \times 60 \times 30$. Для каждого испытания согласно ГОСТ Р 53292 2009 «Огнезащитные составы и вещества для древесины и материалов на ее основе. Общие требования. Методы испытаний» использовалось по 10 образцов [2].

Испытания выполнялись с нанесением разного количества слоев огнезащитного состава.

Данное испытание проводилось на базе лаборатории кафедры «Пожарная и промышленная безопасность» ФГБОУ ВО «Уфимский государственный нефтяной технический университет», расположенной по адресу: Республика Башкортостан, г. Уфа, улица Космонавтов, 1. 


\section{Подготовка к испьтанию}

Для проведения испытания были подготовлены образцы для нанесения огнезащитного состава. Образцы были изготовлены из прямослойной воздушно-сухой древесины сосны с прямоугольных брусков с поперечным сечением $30 \times 60$ мм и длиной вдоль волокон 150 мм, отклонение от размеров не превышало 1 мм.

Перед испытанием все образцы древесины перед нанесением ОС кондиционировали в эксикаторе $\mathrm{c}$ насыщенным раствором цинка азотнокислого 6-водного при температуре $(23 \pm 5){ }^{\circ} \mathrm{C}$. Кондиционирование было прекращено, когда изменение массы образцов между двумя последующими взвешиваниями, проведенными через 24 ч, составляло не более 0,2 г. Процесс кондиционирования представлен на рисунке 1.

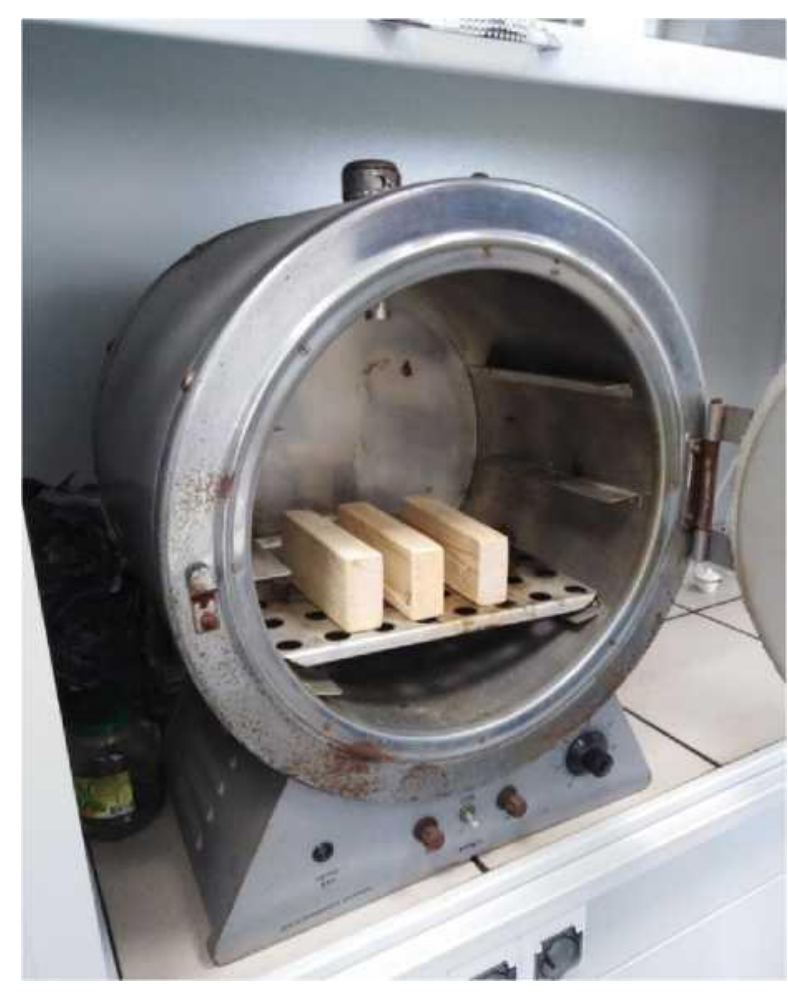

Рисунок 1. Процесс кондиционирования образцов

После подготовки образцов их взвешивали с помощью электронных весов. Результаты взвешивания занесены в таблицу 1. 
Таблица 1. Масса образцов перед испытанием, г

\begin{tabular}{|c|c|c|c|}
\hline \multicolumn{2}{|c|}{ Образцы для нанесения 1-го слоя } & \multicolumn{2}{|c|}{ Образцы для нанесения 2-х слоев } \\
\hline Образец 1 & 121,98 & Образец 1 & 111,75 \\
\hline Образец 2 & 119,67 & Образец 2 & 108,52 \\
\hline Образец 3 & 121,41 & Образец 3 & 112,03 \\
\hline Образец 4 & 120,85 & Образец 4 & 112,41 \\
\hline Образец 5 & 122,54 & Образец 5 & 109,61 \\
\hline Образец 6 & 120,96 & Образец 6 & 111,04 \\
\hline Образец 7 & 119,34 & Образец 7 & 110,73 \\
\hline Образец 8 & 119,83 & Образец 8 & 109,86 \\
\hline Образец 9 & 122,64 & Образец 9 & 108,97 \\
\hline Образец 10 & 121,08 & Образец 10 & 110,51 \\
\hline
\end{tabular}

В период кондиционирования образцов производилась подготовка компонентов для состава и дальнейшее их смешивание в огнезащитный состав.

Были подготовлены жидкое натриевое стекло, наноразмерный диоксид кремния.

Также было подготовлено оборудование для взвешивания компонентов и емкость, в которой происходило смешивание жидкого стекла и диоксида кремния [19-21].

При взвешивании компонентов было определено их весовое соотношение, которое составило 95 г жидкого стекла на 5 г диоксида кремния. Смешивание компонентов производилось в стеклянной емкости при помощи стеклянной палочки.

Отмеренное количество диоксида кремния порционно вводилось в отмеренное количество жидкого стекла. Состав размешивали в течение 30 мин до образования однородной массы.

После того как состав был готов, его при помощи кисти наносили на все образцы.

После высыхания образцы взвешивали. Результаты взвешивания были занесены в таблицу 2. 
Таблица 2. Масса образцов после нанесения и высыхания 1-го слоя, г

\begin{tabular}{|c|c|c|c|c|c|}
\hline \multicolumn{2}{|c|}{ Образцы для нанесения 1-го слоя } & \multicolumn{2}{c|}{ Образцы для нанесения 2-х слоев } \\
\hline № образца & 24 ч & 48 ч & № образца & 24 ч & 48 ч \\
\hline Образец 1 & 130,06 & 129,13 & Образец 1 & 120,31 & 119,58 \\
\hline Образец 2 & 127,51 & 125,89 & Образец 2 & 117,77 & 117,06 \\
\hline Образец 3 & 129,99 & 128,37 & Образец 3 & 120,89 & 120,08 \\
\hline Образец 4 & 129,21 & 128,11 & Образец 4 & 121,58 & 120,91 \\
\hline Образец 5 & 130,37 & 129,72 & Образец 5 & 119,36 & 118,64 \\
\hline Образец 6 & 128,06 & 126,75 & Образец 6 & 121,01 & 120,13 \\
\hline Образец 7 & 126,60 & 125,95 & Образец 7 & 120,11 & 119,36 \\
\hline Образец 8 & 126,92 & 125,24 & Образец 8 & 118,94 & 118,02 \\
\hline Образец 9 & 131,28 & 130,66 & Образец 9 & 118,03 & 117,25 \\
\hline Образец 10 & 131,04 & 129,97 & Образец 10 & 119,96 & 118,92 \\
\hline
\end{tabular}

Через 48 ч после нанесения 1-го слоя огнезащитного состава на 10-ти отобранных образцах кистью был нанесен 2-ой слой состава. Вид образцов после нанесения 1-го и 2-го слоя огнезащитного состава представлен на рисунке 2 .

По истечении 48 ч после нанесения 2-го слоя состава все образцы взвешивали. Масса образцов перед испытанием представлена в таблице 3.

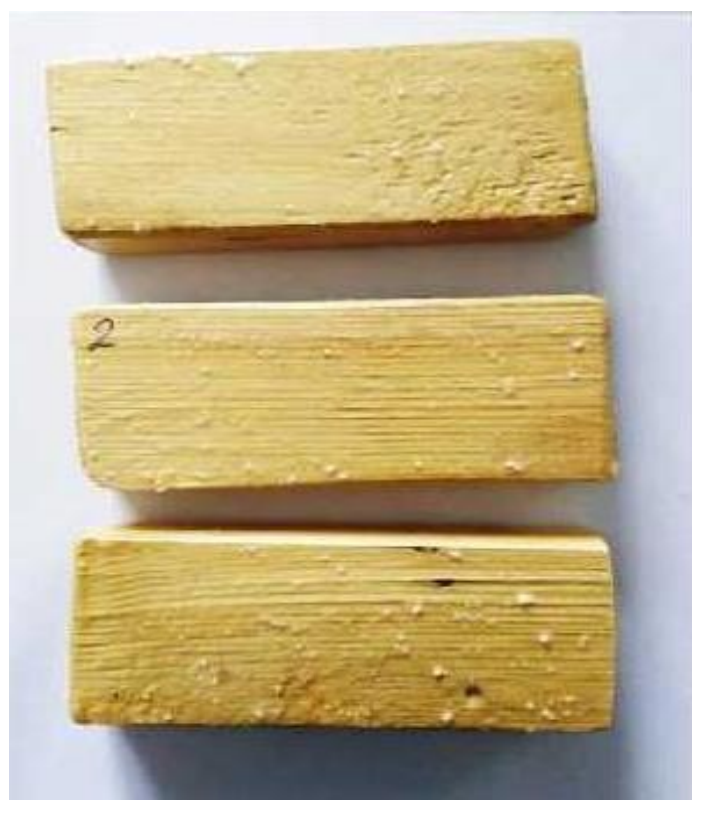

a)

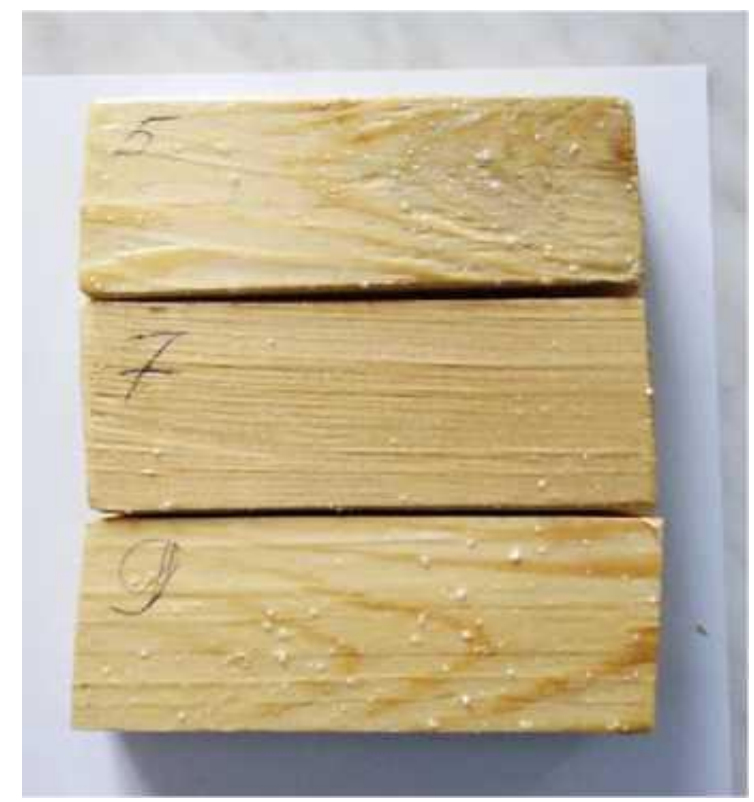

б)

a) после нанесения 1-го слоя; б) после нанесения 2-го слоя

Рисунок 2. Вид образцов после нанесения огнезащитного состава 
Таблица 3. Масса образцов перед испытанием, г

\begin{tabular}{|c|c|c|c|}
\hline \multicolumn{2}{|c|}{ Образцы покрытые 1 слоем } & \multicolumn{2}{c|}{ Образцы покрытые 2 слоями } \\
\hline Образец 1 & 128,76 & Образец 1 & 121,66 \\
\hline Образец 2 & 124,45 & Образец 2 & 118,05 \\
\hline Образец 3 & 127,29 & Образец 3 & 122,14 \\
\hline Образец 4 & 127,32 & Образец 4 & 122,49 \\
\hline Образец 5 & 128,47 & Образец 5 & 120,29 \\
\hline Образец 6 & 127,58 & Образец 6 & 122,57 \\
\hline Образец 7 & 124,72 & Образец 7 & 121,22 \\
\hline Образец 8 & 124,06 & Образец 8 & 119,97 \\
\hline Образец 9 & 129,43 & Образец 9 & 118,93 \\
\hline Образец 10 & 128,24 & Образец 10 & 120,78 \\
\hline
\end{tabular}

Для проведения последнего этапа исследования были необходимы: образцы, покрытые огнезащитным составом, установка «Керамическая труба», секундомер, источник огня, электронные весы, тетрадь и ручка для записи результатов.

Испытание образцов проводилось на установке «Керамическая труба», вид которой представлен на рисунке 3.

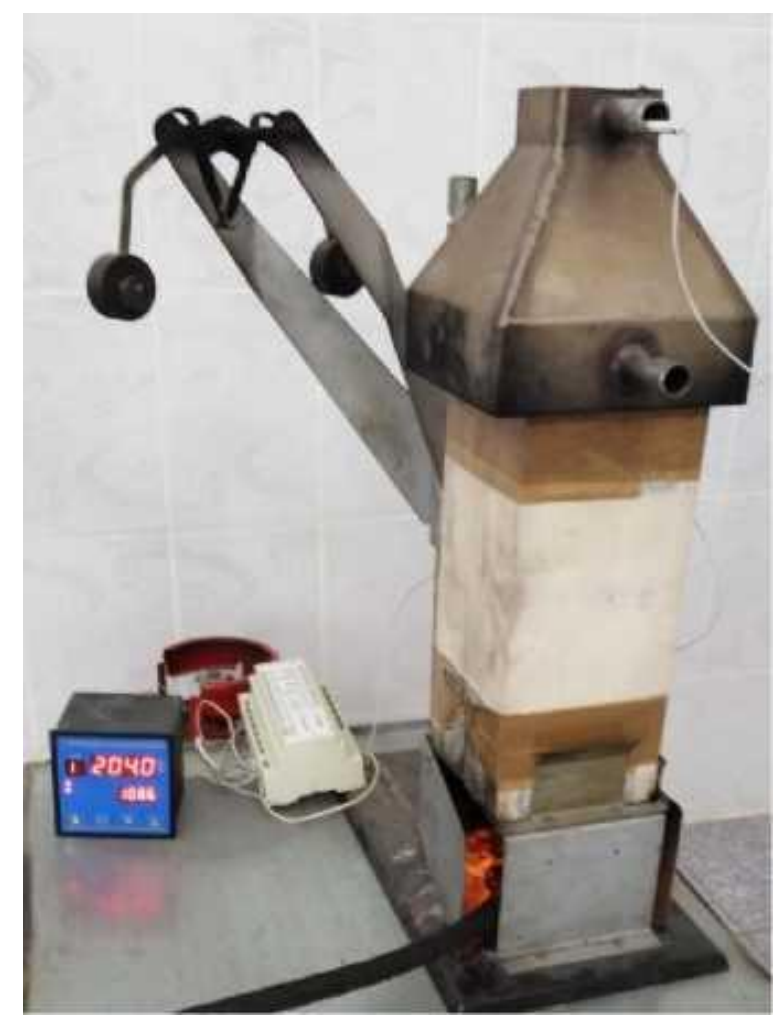

Рисунок 3. Установка «Керамическая труба» 


\section{2. Подготовка установки к испытанию и испытание образцов}

Керамический короб переводили в горизонтальное положение и зажигали газовую горелку, устанавливали высоту пламени от 15 до 25 см. После этого керамический короб возвращали в вертикальное положение, переводили зонт в рабочее положение над коробом и регулировали расход газа так, чтобы температура, регистрируемая термоэлектрическим преобразователем, в течение 5 мин была равна $(200 \pm 5){ }^{\circ} \mathrm{C}$. Дополнительное регулирование температуры может осуществляться путем регулирования подачи воздуха в зону горения материала с помощью створок металлической подставки.

Первыми тепловому воздействию подвергали образцы, покрытые 1-м слоем огнезащитного состава. Зонт отводили, испытываемый образец, закрепленный в держателе, опускали в керамический короб, одновременно включали секундомер и возвращали зонт в рабочее положение. Образец держали в пламени горелки в течение 2 мин. Расход газа в процессе испытания был постоянным. Через 2 мин подачу газа в горелку прекращали, образец оставляли в приборе для остывания. Образец, подвергшийся воздействию огня, представлен на рисунке 4.

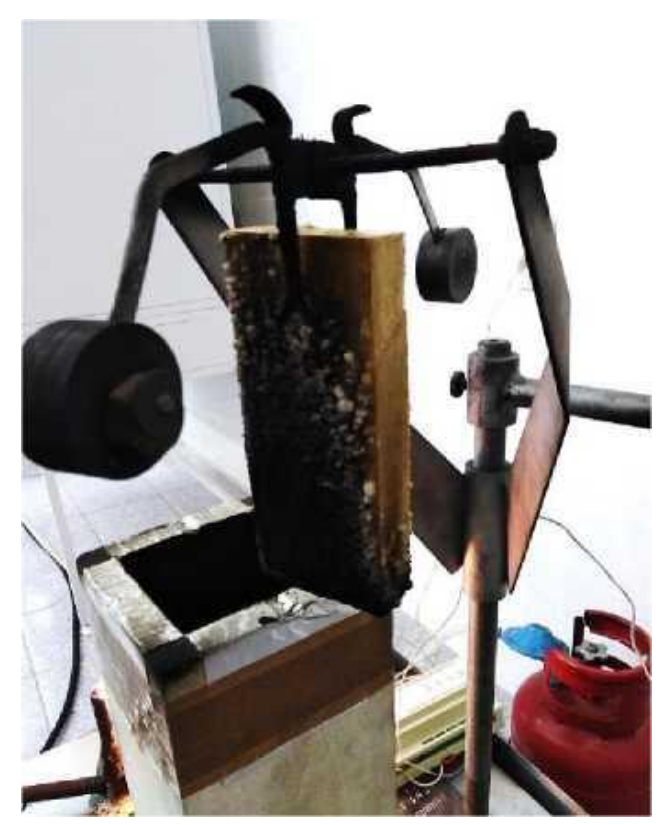

Рисунок 4. Остывание образца в установке «Керамическая труба» 
После остывания (температура отходящих газов в верхнем патрубке зонта равна комнатной) оставшуюся часть образца извлекали из керамического короба и взвешивали, результат округляли до 0,1 г.

Такую процедуру проводили с каждым образцом.

Затем испытания проводились на образцах, покрытых 2-мя слоями огнезащитного состава. По окончанию испытания все образцы взвешивались, результаты были занесены в таблицу 4.

Внешний вид некоторых образцов после испытания представлен на рисунке 5.

Таблица 4. Масса образцов после испытания, г

\begin{tabular}{|c|c|c|c|}
\hline \multicolumn{2}{|c|}{ Образцы покрытые 1 слоем } & \multicolumn{2}{|c|}{ Образцы покрытые 2 слоями } \\
\hline Образец 1 & 124,83 & Образец 1 & 117,69 \\
\hline Образец 2 & 120,17 & Образец 2 & 115,13 \\
\hline Образец 3 & 123,94 & Образец 3 & 119,13 \\
\hline Образец 4 & 124,03 & Образец 4 & 119,58 \\
\hline Образец 5 & 124,58 & Образец 5 & 117,31 \\
\hline Образец 6 & 123,35 & Образец 6 & 119,29 \\
\hline Образец 7 & 120,33 & Образец 7 & 118,75 \\
\hline Образец 8 & 120,39 & Образец 8 & 116,53 \\
\hline Образец 9 & 124,59 & Образец 9 & 115,78 \\
\hline Образец 10 & 127,97 & Образец 10 & 117,57 \\
\hline
\end{tabular}

Огнезащитный состав, которым покрывались образцы, при воздействии высокой температуры вспучивается, тем самым позволяет сдержать распространение огня и повышение температуры.

В случае пропитки образцов способами, обеспечивающими глубокое проникновение ОС, общее поглощение R, кг/м, определяют по формуле [2]:

$$
R=\frac{m_{1}-m_{2}}{V},
$$

где $m_{1}$ - масса образца после пропитки, кг;

$m_{2}$ - масса образца перед пропиткой, кг;

$V$ - объем образца, $\mathbf{m}^{3}$. 


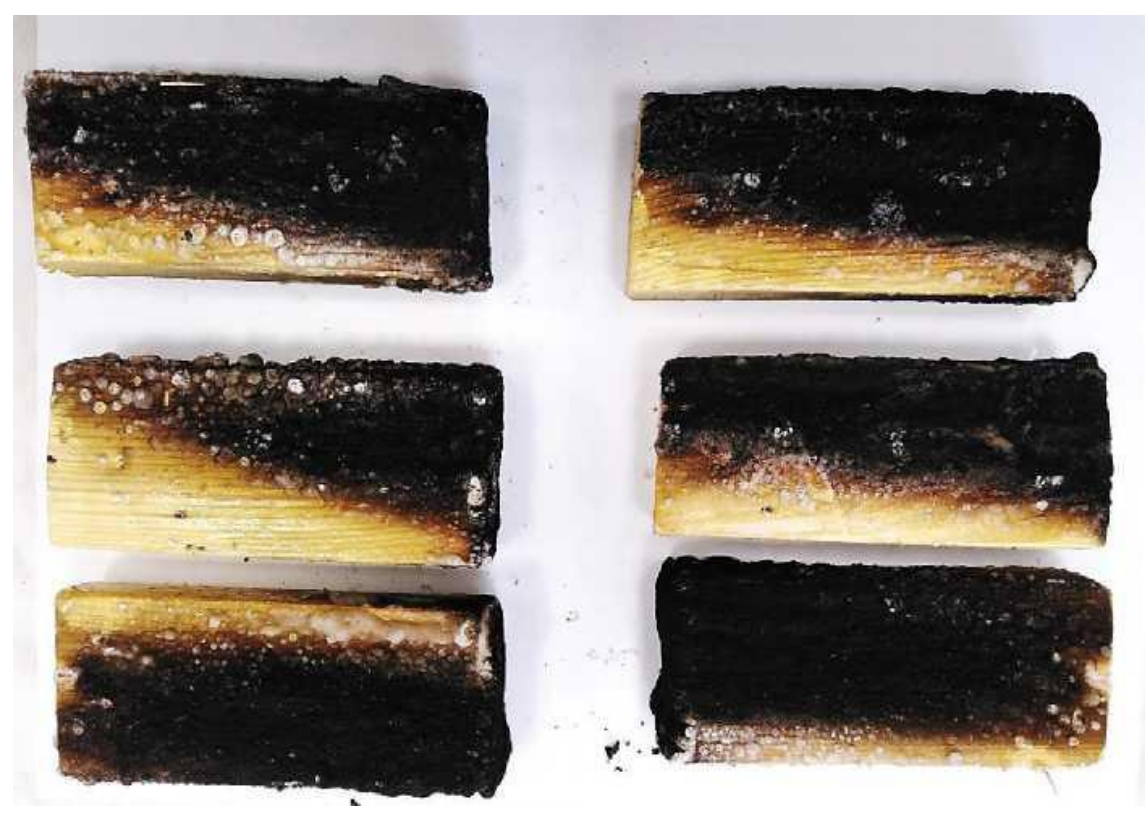

Рисунок 5. Вид образцов после испытания

Перед испытанием обработанные и высушенные образцы древесины кондиционируют и взвешивают, результат округляют до 0,1 г.

Испытания проводят не менее чем на 10 образцах в вытяжном шкафу с принудительной вентиляцией, скорость движения воздуха не более 5 м/с.

Потерю массы испытанного образца $P_{i}, \%$, вычисляют по формуле [2]:

$$
P_{i}=\frac{\left(m_{1 i}-m_{2 \mathrm{i}}\right) \cdot 100}{m_{1 i}},
$$

где $m_{1 i}-$ масса образца до испытания, г;

$m_{2 i}$ - масса образца после испытания, г;

$i$ - номер образца.

Полученный результат вычисления округляют до $0,1 \%$.

После испытания определяют среднее арифметическое значение потери массы десяти испытанных образцов. Вместо образцов, для которых не выполняются неравенства (3) и (4), испытывают новые образцы и вновь определяют среднее арифметическое значение потери массы [2]:

$$
\begin{gathered}
\left|P_{\text {ср }}-P_{i}\right| \leq 3 \text { при } P_{\text {ср }} \leq 9 \\
\left|P_{\text {ср }}-P_{i}\right| \leq 5 \text { при } 9<P_{\text {ср }} \leq 25,
\end{gathered}
$$


где $P_{c p}-$ среднее арифметическое значение потери массы десяти испытанных образцов, \%;

$P_{i}$ - значение потери массы одного из десяти испытанных образцов, \%.

За результат испытания принимают среднее арифметическое значение не менее 10 определений, округленное до целого числа процентов.

По результатам испытания устанавливают группу огнезащитной эффективности испытанного ОС при данном способе его применения. При потере массы не более 9 \% для ОС устанавливают I группу огнезащитной эффективности.

При потере массы более 9 \%, но не более 25 \% для ОС устанавливают II группу огнезащитной эффективности. При потере массы более $25 \%$ считают, что данный состав не обеспечивает огнезащиту древесины и не является огнезащитным [2].

\section{3. Расчет потери массы испытуемых образцов}

Потерю массы испытанного образца $\mathrm{P}_{\mathrm{i}}$, \%, вычисляют по формуле (2).

Полученный результат вычисления округляют до 0,1\%.

После испытания определяют среднее арифметическое значение потери массы 10 испытанных образцов. Вместо образцов, для которых не выполняются неравенства (3) и (4), испытывают новые образцы и вновь определяют среднее арифметическое значение потери массы.

Расчет потери массы 1 образца

$$
\begin{gathered}
P_{1}=\frac{\left(m_{11}-m_{21}\right) \cdot 100}{m_{11}}=\frac{(121,98-124,83) \cdot 100}{121,98}=-2,34 \% \\
\left|P_{\mathrm{cp}}-P_{i}\right| \leq 3 \\
|-1,63-(-2,3)|=0,67 \leq 3
\end{gathered}
$$

Расчет потери массы остальных образцов представлен в таблице 5. 
Таблица 5. Расчет потери массы образцов

\begin{tabular}{|c|c|c|c|}
\hline \multicolumn{2}{|c|}{ Образцы покрытые 1-и слоем } & \multicolumn{2}{|c|}{ Образцы покрытые 2-мя слоями } \\
\hline № образца & $\mathrm{P}_{\mathrm{i}}, \%$ & № образца & $\mathrm{P}_{\mathrm{i}}, \%$ \\
\hline Образец 1 & $-2,3$ & Образец 1 & $-5,3$ \\
\hline Образец 2 & $-0,4$ & Образец 2 & $-6,1$ \\
\hline Образец 3 & $-2,1$ & Образец 3 & $-6,3$ \\
\hline Образец 4 & $-2,6$ & Образец 4 & $-6,4$ \\
\hline Образец 5 & $-1,7$ & Образец 5 & $-7,0$ \\
\hline Образец 6 & $-1,9$ & Образец 6 & $-7,4$ \\
\hline Образец 7 & $-0,8$ & Образец 7 & $-7,2$ \\
\hline Образец 8 & $-0,5$ & Образец 8 & $-6,1$ \\
\hline Образец 9 & $-1,6$ & Образец 9 & $-6,2$ \\
\hline Образец 10 & $-2,4$ & Образец 10 & $-6,4$ \\
\hline $\mathrm{P}_{\mathrm{cp},} \%$ & $-1,63$ & $\mathrm{P}_{\mathrm{cp},} \%$ & $-6,44$ \\
\hline
\end{tabular}

Из таблицы 5 видно, что потеря массы каждого образца не превышает $9 \%$, что позволяет отнести огнезащитные составы к I группе огнезащитной эффективности.

Главным достоинством разработанного нами состава (предложено название «Спутник-2020») является то, что он относится к I группе огнезащитной эффективности. Также к достоинствам можно отнести простой состав и дешевизну.

Для определения устойчивости к механическим воздействиям и сроков эксплуатации необходимо проводить дополнительные испытания.

\section{Заключение}

Огнезащита создана для повышения фактического предела огнестойкости строительных конструкций до необходимых значений и для сдерживания предела распространения огня по конструкциям и кабельным линиям и для снижения горючести материалов, а также для сокращения 
опасных факторов пожара (дымообразования, выделение газообразных токсичных веществ и др.) [1, 22, 23].

Среди огнезащитных средств выделяют огнезащитные составы для древесины и материалов на ее основе, для металлических и железобетонных конструкций, для кабелей и др.

История огнезащиты началась еще в 1812 г., когда при строительстве новых домов, для их защиты от огня, бревенчатые стены обмазывали глиной, затем деревянные конструкции стали покрывать известковым раствором.

Однако на научную основу дело огнезащиты строительных материалов и конструкций было поставлено только в послереволюционное время. Научными изысканиями в области огнезащиты строительных материалов и конструкций стал заниматься химический отдел Центральной научноисследовательской лаборатории (1929 г), а затем Центральный научноисследовательский институт противопожарной обороны (ЦНИИПО, 1937 г.) [24].

Первое упоминание об огнезащитных средствах появилось в 1949 г.

В начале своего развития были огнезащитные средства только для древесины, это было связано с тем, что наиболее популярным строительным материалом было дерево.

Со временем при появлении новых строительных материалов появились огнезащитные средства для стальных и железобетонных строительных конструкций, а также огнезащитные средства для кабелей.

На современном этапе развитие огнезащитных средств не останавливается. Сейчас все больше появляются новые строительные материалы, в связи с этим и огнезащитные средства обновляются.

Первыми документами, связанными с пожарным делом, считаются «Наказ о городском благочинии» и «Соборное уложение».

В 1832 г. был издан «Строительный устав», в котором был представлен свод законов (правил) по планировке населенных мест и строительству 
зданий, в том числе содержал и мероприятия по обеспечению пожарной безопасности [25].

Следующим документом стал Общесоюзный стандарт (ОСТ 90015-39), регламентирующий требования пожарной безопасности в области строительства.

Сейчас разработано множество нормативных документов, связанных с противопожарным нормированием в области огнезащиты.

В рамках данной работы было предложено разработать новый огнезащитный состав для древесины и материалов на ее основе.

Для этого был проведен патентный поиск, в результате которого был выбран патент RU 2458951, состоящий из жидкого стекла и нанооксида алюминия, в процентном соотношении $95 \%$ к $5 \%$ \% разработанном составе было решено заменить нанооксид алюминия на диоксид кремния.

По своим свойствам они не сильно отличаются, но цена за 1 кг диоксида кремния ниже, чем к нанооксида алюминия.

На первом этапе испытаний были подготовлены компоненты для огнезащитного состава и образцы, на которые наносился разработанный состав.

На втором этапе был проведен эксперимент, по результатам которого удалось определить, что эксперимент был проведен успешно, разработанное огнезащитное покрытие было отнесено к I группе огнезащитной эффективности.

\section{Выводы}

Разработан на основе недорогих материалов новый высокоэффективный огнезащитный состав для строительных конструкций из древесины и материалов на ее основе.

Обосновано достижение необходимой огнезащитной эффективности разработанного состава. Разработанное огнезащитное покрытие отнесено к 
I группе огнезащитной эффективности. Его применение позволит повысить уровень пожарной безопасности строительных объектов.

\section{Список использованных источников}

1. Федеральный закон от 22.07.2008 № 123-Ф3 «Технический регламент о требованиях пожарной безопасности» (с посл. изм. и доп. от 27.12.2018 г.)» // Информационно-правовое обеспечение «Гарант». URL: http://ivo.garant.ru/\#/document/12161584/paragraph/1:0 (дата обращения: 21.10.2020).

2. ГОСТ Р 53292-2009. Огнезащитные составы и вещества для древесины и материалов на ее основе. Общие требования. Методы испытаний // Информационно-правовое обеспечение «Гарант». URL: https://base.garant.ru/5923183/ (дата обращения: 21.10.2020).

3. Информационно-аналитический бюллетень за 2018 год // MЧC. URL: http://www.mchs.gov.ru/upload/site1/document_file/KkgL7B4oAa.pdf (дата обращения: 21.10.2020).

4. ГОСТ Р 53295-2009. Средства огнезащиты для стальных конструкций. Общие требования. Метод определения огнезащитной эффективности // Информационно-правовое обеспечение «Гарант». URL: https://base.garant.ru/195893/ (дата обращения: 22.10.2020).

5. ГОСТ Р 53310-2009. Проходки кабельные, вводы герметичные и проходы шинопроводов. Требования пожарной безопасности. Методы испытаний на огнестойкость // Информационно-правовое обеспечение «Гарант». URL: https://base.garant.ru/199042/ (дата обращения: 22.10.2020).

6. ГОСТ 30247.0-94. Конструкции строительные. Методы испытаний на огнестойкость. Общие требования // Информационно-правовое обеспечение «Гарант». URL: https://base.garant.ru/3923021 (дата обращения: 24.10.2020).

7. СНиП 21-01-97. Пожарная безопасность зданий и сооружений (с Изменениями № 1, 2). М.: ГУП ЦПП, 2002. 21 с. 
8. СП 2.13130.2012. Системы противопожарной защиты. Обеспечение огнестойкости объектов защиты // Информационно-правовое обеспечение «Гарант». URL: https://www.garant.ru/products/ipo/prime/doc/70177150 (дата обращения: 25.10.2020).

9. СТО 43.29.11. Огнезащита деревянных конструкций в построечных условиях // Докипедия. URL: https://dokipedia.ru/document/1723328 (дата обращения: 25.10.2020).

10. Пат. 2272057 РФ, МПК С 09 D 133/00. Состав для получения огнезащитных покрытий / В.А. Назаренко, С.В. Костиков, С.Ф. Симаков, С.В. Андреев. 2004125101/04, Заявлено 18.08.2004; Опубл. 20.03.2006. Бюл. 8.

11. Пат. 2379322 РФ, МПК С 09 D 183/04. Композиция для огне- и биозащиты древесины / А.И. Катанаев, Р.С. Миргазитова. 2008130264/04, Заявлено 21.07.2008; Опубл. 20.01.2010. Бюл. 2.

12. Пат. 2458951 РФ, МПК С 09 D 5/18. Состав для огнезащитного покрытия с использованием нанооксида алюминия / В.В. Петров, Е.А. Тютина, А.А. Шпилева, Н.В. Захарова, Н.В. Бердников, Д.С. Денисенко, О.А. Грачева. 2011109969/05, Заявлено 16.03.2011; Опубл. 20.08.2012. Бюл. 23.

13. Пат. 2458964 РФ, МПК С 09 К 21/14. Состав для получения огнезащитного покрытия / И.А. Годунов, Н.Г. Кузнецов, В.Н. Овчинников, В.В. Авдеев. 2011112300/05, Заявлено 31.03.2011; Опубл. 20.08.2012. Бюл. 23.

14. Пат. 2467040 РФ, МПК С 09 D 5/18. Сырьевая смесь для огнезащитного покрытия / Н.Г. Василовская, И.Г. Енджиевская, О.В. Слакова, И.П. Авсиевич. 2011141404/05, Заявлено 12.10.2011; Опубл. 20.11.2012. Бюл. 32.

15. Пат. 2499809 РФ, МПК С 09 D 5/18. Состав для изготовления огнезащитного покрытия / О.Н. Емельянова, Е.П. Кудрявцева, А.Н. Большакова, Р.А. Санду. 2012133432/05, Заявлено 06.08.2012; Опубл. 27.11.2013. Бюл. 3. 
16. Пат. 2523825 РФ, МПК С 09 К 21/04. Огнезащитный состав и способ его получения / И.М. Миронович, Н.И. Луговская. 2011132974/05, Заявлено 08.08.2011; Опубл. 27.07.2014. Бюл. 21.

17. Программа для ЭВМ 2018610396 РФ. Программа для расчета параметров пожаров и аварийных розливов нефти / Р.А. Исмаков, Ф.Ш. Хафизов, И.Ф. Хафизов, А.А. Шарафутдинов, Р.Р. Курбанаев, Р.Р. Каримов. 2017661649 Заявлено 14.11.2017; Опубл. 10.01.2018.

18. Программа для ЭВМ 2018610351 РФ. Программа моделирования и расчета водопенных коммуникаций пожарных автоцистерн / Р.Н. Бахтизин, О.А. Баулин, Ф.Ш. Хафизов, И.Ф. Хафизов, А.А. Шарафутдинов, А.Т. Шайдуллин. 2017661738 Заявлено 14.11.2017; Опубл. 10.01.2018.

19. Кремния диоксид // ChemistLab.

URL: http://chemistlab.rU/publ/k/kremnija_dioksid/10-1-0-605 (дата обращения: 26.10.2020).

20. Жидкое стекло - состав, свойства и применение // Строитель Инфо. URL: https://stroitelinfo.ru/zhidkoe-steklo-primenenie-vidy-svojstva (дата обращения: 26.10.2020).

21. Корольченко А.Я., Корольченко О.Н. Средства огнезащиты. Справочник. М.: ПожНаука, 2006. 258 с.
22. Gazizov
A.M., Kuznetsova
O.V.,
Sharafutdinov
A.A., Shaimuhametova K.M. Improvement of Fire Retardant Properties of Wood Materials // IOP Conference Series: Materials Science and Engineering. 2020. Vol. 919. P. 062014. DOI: 10.1088/1757-899X/919/6/062014.

\section{Sharafutdinov A.A., Khafizov F.S., Khafizov I.F., Krasnov A.V.,} Akhmethafizov A.V., Zakirova V.I., Khafizova A.N. Development of a Method for Calculating Fire and Oil Spills Parameters // 28th Russian Conference on Mathematical Modelling in Natural Sciences, RuMoNaS 2019: Materials of AIP Conference Proceedings. Perm, Russia. 2020. Vol. 2216. P. 070004. DOI: $10.1063 / 5.0003843$. 
24. Khafizov F.S., Gazizov A.M., Khafizov I.F., Sharafutdinov A.M. Evaluation of the Mobile Simulator for Fire Protection Training // Computer Systems, Applications and Software Engineering, CSASE 2018: Materials of the Annual Scientific International Conference. Nizhniy Tagil, Russia. 2018. Vol. 2131. URL: http://ceur-ws.org/Vol-2131/paper6.pdf (дата обращения: 27.10.2020).

25. Газизов А.М., Кузнецова О.В., Шарафутдинов А.А., Еникеев М.И. Повышение стойкости композиционного древесного материала // Сетевое издание «Нефтегазовое дело». 2018. № 4. С. 182-193. URL: http://ogbus.ru/files/ogbus/issues/4_2018/ogbus_4_2018_p182193_GazizovAM_ru.pdf (дата обращения: 27.10.2020). DOI: 10.17122/ogbus2018-4-182-193.

\section{References}

1. Federal'nyi zakon ot 22.07.2008 № 123-FZ «Tekhnicheskii reglament o trebovaniyakh pozharnoi bezopasnosti» (s posl. izm. i dop. ot 27.12.2018 g.) [RF Federal Law of July 22, 2008 No. 123-FZ «Technical Regulations on Fire Safety Requirements» (with the Additions and Amendments of December 27, 2018)]. Informatsionno-pravovoe obespechenie «Garant». Available at: http://ivo.garant.ru/\#/document/12161584/paragraph/1:0 (accessed 21.10.2020). [in Russian].

2. GOST R 53292-2009. Ognezashchitnye sostavy i veshchestva dlya drevesiny i materialov na ee osnove. Obshchie trebovaniya. Metody ispytanii [State Standard R 53292-2009. Fire Retardant Compositions and Substances for Wood. General Requirements. Test Methods]. Informatsionno-pravovoe obespechenie «Garant». Available at: https://base.garant.ru/5923183/ (accessed 21.10.2020). [in Russian]. 
3. Informatsionno-analiticheskii byulleten' za 2018 god [Information and Analytical Bulletin for 2018]. MChS - Ministry of Emergencies. URL: http://www.mchs.gov.ru/upload/site1/document_file/KkgL7B4oAa.pdf (data obrashcheniya: 21.10.2020).

4. GOST R 53295-2009. Sredstva ognezashchity dlya stal'nykh konstruktsii. Obshchie trebovaniya. Metod opredeleniya ognezashchitnoi effektivnosti [State Standard R 53295-2009. Fire Retardant Compositions for Steel Constructions. General Requirement. Method for Determining Fire Retardant Efficiency]. Informatsionno-pravovoe obespechenie «Garant». Available at: https://base.garant.ru/195893 (accessed 22.10.2020). [in Russian].

5. GOST R 53310-2009. Prokhodki kabel'nye, vvody germetichnye i prokhody shinoprovodov. Trebovaniya pozharnoi bezopasnosti. Metody ispytanii na ognestoikost' [State Standard R 53310-2009. Through Penetration for Cables, Hermetic Inputs and Through Penetration of Electric Current Types. Requirements of Fire Safety. Fire Resistance Test Methods]. Informatsionnopravovoe obespechenie «Garant». Available at: https://base.garant.ru/199042 (accessed 22.10.2020). [in Russian].

6. GOST 30247.0-94. Konstruktsii stroitel'nye. Metody ispytanii na ognestoikost'. Obshchie trebovaniya [State Standard 30247.0-94. Elements of Building Constructions. Fire-Resistance Test Methods. General Requirements]. Informatsionno-pravovoe obespechenie «Garant». Available at: https://base.garant.ru/3923021 (accessed 24.10.2020). [in Russian].

7. SNiP 21-01-97. Pozharnaya bezopasnost' zdanii i sooruzhenii (s Izmeneniyami № 1, 2) [SNiP 21-01-97. Fire Safety of Buildings and Works (with Amendments No. 1, 2)]. Moscow, GUP TsPP Publ., 2002. 21 p. [in Russian].

8. SP 2.13130.2012. Sistemy protivopozharnoi zashchity. Obespechenie ognestoikosti ob"ektov zashchity [SP 2.13130.2012. Systems of Fire Protection. Fire-Resistance Security of Protecting Units]. Informatsionno-pravovoe obespechenie «Garant». Available at: https://www.garant.ru/products/ipo/prime/ doc/70177150/ (accessed 25.10.2020). [in Russian]. 
9. STO 43.29.11. Ognezashchita derevyannykh konstruktsii v postroechnykh usloviyakh [STO 43.29.11. Fire Protection of Wooden Structures in Building Conditions]. Dokipediya. Available at: https://dokipedia.ru/document/1723328 (accessed 25.10.2020). [in Russian].

10. Nazarenko V.A., Kostikov S.V., Simakov S.F., Andreev S.V. Sostav dlya polucheniya ognezashchitnykh pokrytii [Composition for Obtaining Fire Retardant Coatings]. Patent RF, No. 2272057, 2006. [in Russian].

11. Katanaev A.I., Mirgazitova R.S. Kompozitsiya dlya ogne- i biozashchity drevesiny [Composition for Fire and Bio-Protection of Wood]. Patent RF, No. 2379322, 2010. [in Russian].

12. Petrov V.V., Tyutina E.A., Shpileva A.A., Zakharova N.V., Berdnikov N.V., Denisenko D.S., Gracheva O.A. Sostav dlya ognezashchitnogo pokrytiya s ispol'zovaniem nanooksida alyuminiya [Composition for Fire Retardant Coating Using Nano Alumina]. Patent RF, No. 2458951, 2012. [in Russian].

13. Godunov I.A., Kuznetsov N.G., Ovchinnikov V.N., Avdeev V.V. Sostav dlya polucheniya ognezashchitnogo pokrytiya [Composition for Obtaining a Fire Retardant Coating]. Patent RF, No. 2458964, 2012. [in Russian].

14. Vasilovskaya N.G., Endzhievskaya I.G., Slakova O.V., Avsievich I.P. Syr'evaya smes' dlya ognezashchitnogo pokrytiya [Raw Mix for fire Retardant Coating]. Patent RF, No. 2467040, 2012. [in Russian].

15. Emelyanova O.N., Kudryavtseva E.P., Bolshakova A.N., Sandu R.A. Sostav dlya izgotovleniya ognezashchitnogo pokrytiya [Composition for the Manufacture of Fire Retardant Coating]. Patent RF, No. 2499809, 2013. [in Russian].

16. Mironovich I.M., Lugovskaya N.I. Ognezashchitnyi sostav i sposob ego polucheniya [Fire Retardant Composition and Method of Obtaining it]. Patent RF, No. 2523825, 2014. [in Russian].

17. Ismakov R.A., Khafizov F.Sh., Khafizov I.F., Sharafutdinov A.A., Kurbanaev R.R., Karimov R.R. Programma dlya rascheta parametrov pozharov i avariinykh rozlivov nefti [Program for Calculating the Parameters of Fires and Emergency Oil Spills]. Computer Program RF, No. 2018610396, 2018. [in Russian]. 
18. Bakhtizin R.N., Baulin O.A., Khafizov F.Sh., Khafizov I.F., Sharafutdinov A.A., Shaidullin A.T. Programma modelirovaniya i rascheta vodopennykh kommunikatsii pozharnykh avtotsistern [Program for Modeling and Calculating Water-Foam Communications for Fire-Fighting Tankers]. Computer Program RF, No. 2018610351, 2017. [in Russian].

19. Kremniya dioksid [Silicon Dioxide]. ChemistLab. Available at: http://chemistlab.rU/publ/k/kremnija_dioksid/10-1-0-605 (accessed 26.10.2020). [in Russian].

20. Zhidkoe steklo - sostav, svoistva i primenenie [Liquid Glass Composition, Properties and Application]. Stroitel' Info. Available at: https://stroitelinfo.ru/zhidkoe-steklo-primenenie-vidy-svojstva (accessed 26.10.2020). [in Russian].

21. Korolchenko A.Ya., Korolchenko O.N. Sredstva ognezashchity. Spravochnik [Fire Protection Means. Directory]. Moscow, Pozhnauka Publ., 2006. 258 p. [in Russian].

22. Gazizov A.M., Kuznetsova O.V., Sharafutdinov A.A., Shaimuhametova K.M. Improvement of Fire Retardant Properties of Wood Materials. IOP Conference Series: Materials Science and Engineering, 2020, Vol. 919, pp. 062014. DOI: 10.1088/1757-899X/919/6/062014.

23. Sharafutdinov A.A., Khafizov F.S., Khafizov I.F., Krasnov A.V., Akhmethafizov A.V., Zakirova V.I., Khafizova A.N. Development of a Method for Calculating Fire and Oil Spills Parameters. Materials of AIP Conference Proceedings «28th Russian Conference on Mathematical Modelling in Natural Sciences, RuMoNaS 2019». Perm, Russia, 2020, Vol. 2216, pp. 070004. DOI: $10.1063 / 5.0003843$.

24. Khafizov F.S., Gazizov A.M., Khafizov I.F., Sharafutdinov A.M. Evaluation of the Mobile Simulator for Fire Protection Training. Materials of the Annual Scientific International Conference «Computer Systems, Applications and Software Engineering, CSASE 2018». Nizhniy Tagil, Russia, 2018, Vol. 2131. URL: http://ceur-ws.org/Vol-2131/paper6.pdf (accessed 27.10.2020). 
25. Gazizov A.M., Kuznetsova O.V., Sharafutdinov A.A., Enikeev M.I. Povyshenie stoikosti kompozitsionnogo drevesnogo materiala [Increasing the Stability of Composite Wood Material]. Setevoe izdanie «Neftegazovoe delo»Online Edition «Oil and Gas Business», 2018, No. 4, pp. 182-193. URL: http://ogbus.ru/files/ogbus/issues/4_2018/ogbus_4_2018_p182-

193_GazizovAM_ru.pdf (accessed 27.10.2020). DOI: 10.17122/ogbus-2018-4182-193. [in Russian].

\section{Сведения об авторах}

\section{About the authors}

Газизов Асгат Мазхатович, д-р техн. наук, профессор, профессор кафедры «Пожарная и промышленная безопасность», УГНТУ, г. Уфа, Российская Федерация

Asgat M. Gazizov, Doctor of Engineering Sciences, Professor, Professor of Fire and Industrial Safety Department, USPTU, Ufa, Russian Federation

e-mail: ashatgaz@mail.ru

Шарафутдинов Азат Амирзагитович, канд. техн. наук, доцент кафедры «Пожарная и промышленная безопасность», УГНТУ, г. Уфа, Российская Федерация

Azat A. Sharafutdinov, Candidate of Engineering Sciences, Assistant Professor of Fire and Industrial Safety Department, USPTU, Ufa, Russian Federation

e-mail: azat_sharaf@mail.ru

Имамутдинов Салават Адипович, доцент кафедры «Пожарная и промышленная безопасность», УГНТУ, г. Уфа, Российская Федерация

Salavat A. Imamutdinov, Assistant Professor of Fire and Industrial Safety Department, USPTU, Ufa, Russian Federation

e-mail: imamutdin.salavat@gmail.com 
Горячев Георгий Анатольевич, магистрант кафедры «Пожарная и промышленная безопасность», УГНТУ, г. Уфа, Российская Федерация

Grigori A. Goryachev, Undergraduate Student of Fire and Industrial Safety Department, USPTU, Ufa, Russian Federation

e-mail: Goriachev001@gmail.com

Шарафутдинова Анжела Азатовна, лицеист, класс УГНТУ, Физикоматематический лицей № 93, г. Уфа, Российская Федерация

Angela A. Sharafutdinova, Lyceum Student, USPTU class, Physics and Mathematics Lyceum No. 93, Ufa, Russian Federation

e-mail: 1lluntik05@mail.ru 